\title{
INBREEDING AND SEX-BIASED GENE FLOW IN THE ANT FORMICA EXSECTA
}

\author{
Liselotte Sundström,,$^{1,2}$ Laurent Keller, ${ }^{1}$ and Michel Chapuisat ${ }^{1}$ \\ ${ }^{1}$ University of Lausanne, Institute of Ecology, Biology Building, 1015 Lausanne, Switzerland \\ ${ }^{2}$ University of Helsinki, Department of Ecology and Systematics, P. O. Box 65, FIN-00014 Helsinki, Finland \\ E-mail: liselotte.sundstrom@helsinki.fi
}

\begin{abstract}
The objective of this study was to assess breeding and dispersal patterns of both males and females in a monogyne (a single queen per colony) population of ants. Monogyny is commonly associated with extensive nuptial flights, presumably leading to considerable gene flow over large areas. Opposite to these expectations we found evidence of both inbreeding and sex-biased gene flow in a monogyne population of Formica exsecta. We found a significant degree of population subdivision at a local scale (within islands) for queens (females heading established colonies) and workers, but not for colony fathers (the males mated to the colony queens). However, we found little evidence of population subdivision at a larger scale (among islands). More conclusive support for sex-biased gene flow comes from the analysis of isolation by distance on the largest island, and from assignment tests revealing differences in female and male philopatry. The genetic similarity between pairs of queens decreased significantly when geographical distance increased, demonstrating limited dispersal and isolation by distance in queens. By contrast, we found no such pattern for colony fathers. Furthermore, a significantly greater fraction of colony queens were assigned as having originated from the population of residence, as compared to colony fathers. Inbreeding coefficients were significantly positive for workers, but not for mother queens. The queen-male relatedness coefficient of 0.23 (regression relatedness) indicates that mating occurs between fairly close relatives. These results suggest that some monogyne species of ants have complex dispersal and mating systems that can result in genetic isolation by distance over small geographical scales. More generally, this study also highlights the importance of identifying the relevant scale in analyses of population structure and dispersal.
\end{abstract}

Key words.-Ants, dispersal, Formica, genetic structure, inbreeding, monogyny, social insects.

Received August 18, 2002.

A central issue in population genetics is to identify the factors influencing the distribution of genetic variability in wild populations. Traditional models assume that individuals mate at random within homogenous populations, and that males and females have equal dispersal rates (e.g., Wright 1921, 1931, 1943; Weir and Cockerham 1984; Weir 1996). However, these assumptions are frequently violated in nature. In many species, populations are divided into discrete breeding units corresponding to social groups (Sugg et al. 1996). These breeding units differ in a number of characteristics, including the number of breeders per group, the genetic relationships among the breeders, and the extent of variation in parentage among breeders (Wade 1985; Ross 1993, 2001). Variation in social structure and breeding systems affects the effective size of both social groups and populations, and can therefore have a strong impact on the amount of genetic differentiation within and among populations (Chesser 1991; Chesser et al. 1993; Nunney 1993; Sugg et al. 1996; Ross et al. 1997). Moreover, differences in social structure are frequently associated with different mating and dispersal behaviors, which also influence the amount of gene flow among groups and populations (Chesser 1991; Nunney 1993). Hence, variation in social structure and breeding system can lead to complex hierarchical organization with several levels of population substructure (Chesser 1991; Chesser et al. 1993; Sugg et al. 1996; Ross et al. 1997, Ross 2001).

Differences in mating system and modalities of dispersal may also have important effects on the level of inbreeding, and hence the fitness of organisms (Keller et al. 1995; Saccheri et al. 1998; Crnokrak and Roff 1999). One sex commonly disperses more than the other in birds and mammals and this sex-specific dispersal is usually sufficient to minimize inbreeding (Greenwood 1980; Dobson 1982; Dobson et al. 1997; Favre et al. 1997).
Accepted January 29, 2003.

In social organisms, patterns of dispersal and colonization are of special interest, because they can have important consequences for social evolution (Wade and Breden 1981; Breden and Wade 1991; Ross and Keller 1995a). Sex-specific differences in dispersal rates also affect the ability to colonize new areas, because only females can give rise to new populations. Surprisingly, detailed information on the social structure, breeding system, and dispersal of males and females is available for only a few social invertebrates (Ross and Keller 1995a; Shoemaker and Ross 1996; Goodisman and Ross 1998; Chapuisat and Keller 1999). Major obstacles to such comprehensive studies include the difficulty of determining the relevant scale at which dispersal, breeding structure, and genetic differentiation should be measured (Queller 1994), and a lack of suitable genetic markers to obtain the relevant information. To date, the respective dispersal of each sex has never been inferred directly from the genotypes of queens and colony fathers sampled after dispersal. The objective of this study was to obtain such data for the monogyne ant Formica exsecta.

An interesting feature of $F$. exsecta is that it comes in two distinct social forms: a monogyne form, in which colonies have a single egg-laying queen, and a polygyne form, in which colonies have multiple queens. Usually one of the two forms dominates in any particular population (Rosengren et al. 1993). Such intraspecific variation in social organization is common in ants. Monogyne and polygyne forms usually differ in a number of traits besides the number of queens per colony (Keller 1993; Ross and Keller 1995b; Sundström 1995). The most important correlates of queen number are the mating system, and modes of dispersal and colony foundation. Monogyne colonies typically produce queens and males that participate in extensive mating flights and mate 
TABLE 1. F-coefficients in a four-level analysis of variance of population subdivision and inbreeding. The coefficients marked with an asterisk contain the relevant information for population structure and only those estimates are given in Table 2. i, individual; c, colony; $\mathrm{s}$, sector; $\mathrm{p}$, island; t, total population.

\begin{tabular}{|c|c|c|c|}
\hline$F$-coefficient & $\begin{array}{l}\text { Defined as the correlation } \\
\text { between pairs of genes within: }\end{array}$ & Biological interpretation & Applies to \\
\hline$F_{\text {ic }}$ & $\begin{array}{l}\text { individuals, compared to ran- } \\
\text { dom genes within the col- } \\
\text { ony }\end{array}$ & $\begin{array}{l}\text { deviation from H-W equilibrium within colonies-zero } \\
\text { or negative when workers are related }\end{array}$ & $\begin{array}{l}\text { workers (not defined for hap- } \\
\text { loid males) }\end{array}$ \\
\hline$F_{\text {is }}{ }^{*}$ & $\begin{array}{l}\text { the individual, compared to } \\
\text { random genes within the } \\
\text { sector }\end{array}$ & $\begin{array}{l}\text { heterozygote excess or deficiency within sectors-in- } \\
\text { breeding due to non-random mating in the parental } \\
\text { generation }\end{array}$ & $\begin{array}{l}\text { workers, queens (not defined } \\
\text { for haploid males) }\end{array}$ \\
\hline$F_{\mathrm{cs}}$ & $\begin{array}{l}\text { colonies, compared to ran- } \\
\text { dom genes within the sec- } \\
\text { tor }\end{array}$ & $\begin{array}{l}\text { allele frequency differences among colonies within sec- } \\
\text { tors-positive when workers are related }\end{array}$ & workers \\
\hline$F_{\mathrm{sp}} *$ & $\begin{array}{l}\text { the sector, compared to ran- } \\
\text { dom genes within the is- } \\
\text { land }\end{array}$ & $\begin{array}{l}\text { allele frequency differences among sectors within is- } \\
\text { lands }\end{array}$ & $\begin{array}{l}\text { workers, queens, colony fa- } \\
\text { thers }\end{array}$ \\
\hline$F_{\mathrm{pt}}{ }^{*}$ & $\begin{array}{l}\text { the island, compared to ran- } \\
\text { dom genes within the total } \\
\text { population }\end{array}$ & allele frequency differences among islands & $\begin{array}{l}\text { workers, queens, colony fa- } \\
\text { thers }\end{array}$ \\
\hline
\end{tabular}

away from the nest. After dispersal, queens found new colonies independently, with no assistance from workers, or by temporarily parasitizing other species. This has led to the common view that monogyne species form large panmictic populations with no inbreeding (Bourke and Franks 1995; Crozier and Pamilo 1996). However, few studies have used genetic markers to analyze dispersal patterns and population structure in monogyne ants (Pamilo 1983; Sundström 1993; Seppä and Pamilo 1995; Shoemaker and Ross 1996; Ross et al. 1997, 1999). In contrast to the monogyne forms, genetic studies have shown that polygyny is frequently associated with significant population structuring and isolation by distance (Pamilo 1982, 1983; Sundström 1993; Herbers and Grieco 1994; Seppä and Pamilo 1995; Banschbach and Herbers 1996; Shoemaker and Ross 1996; Chapuisat et al. 1997; Ross et al. 1997, 1999; Pedersen and Boomsma 1999a,b).

The objective of this study was to analyze the breeding structure, as well as sex-specific patterns of dispersal for established queens and colony fathers in a monogyne population of the ant Formica exsecta. To this end, we obtained the genotypes of queens, workers, and colony fathers at two DNA-microsatellite and three allozyme loci. We analyzed the correlation of genes across several hierarchical levels of organization: genes in individuals, individual in colonies, colonies in sectors, sectors in islands, and islands in the total population (Table 1). We then inferred the dispersal and mating patterns that best account for the observed distribution of genetic variability at these four hierarchical levels. This enables us to identify the relevant scale of analysis, which is crucial for a correct assessment of dispersal distances and breeding units.

\section{Materials and Methods Study Population}

The study population is located in the archipelago close to the Tvärminne Zoological Station (Hanko, southwestern Finland), and spans over six islands, three of which were included in this study (Fig. 1). Colonies of Formica exsecta typically are found in fairly high densities in meadows as well as on rocky archipelago islands with open grassy patches. The colonies are conspicuous and therefore we were able to locate all colonies in the population. The average distance between neighboring colonies on the island harboring the largest number of nests was $17 \pm 10.8 \mathrm{~m}$. Previous genetic studies have shown that $99 \%$ of the colonies of the study population are monogyne, and that the queens had mated with one to three males (Sundström et al. 1996; Keller et al. 1997; Boomsma and Sundström 1998). Based on allozyme markers and demographic analyses the average queen longevity in this particular population has been estimated to range between 20 and 30 years (Pamilo 1991). In the same study, analyses based on two diallelic allozyme markers suggested inbreeding $(F=0.16)$ in workers. Colonies persist in the same site over many years (presumably the entire life span of the queen), unless severely disturbed (Pamilo 1991; L. Sundström, pers. obs.).

The study population encompasses four hierarchical levels of organization. First, the study site consists of three islands distant by 0.5 to 1 kilometers. Second, the islands are divided into local patches (sectors) isolated by habitat unsuitable for the ants, such as boggy areas, dense forest or ditches. Third, each sector comprises several colonies. Fourth, each colony contains workers that are full- or half-sibs (the offspring of one queen and the male(s) with whom she has mated during the mating flight). Migration between islands necessarily entails dispersal on the wing, whereas dispersal within sectors, and possibly between sectors, may occur on foot.

\section{Sampling and Genotyping}

The data presented here are based on sampling in 1994 and 1995 and comprise 70 colonies on three islands within a radius of $1 \mathrm{~km}$ (Fig. 1). Each study island harbored 10 or more colonies. To avoid biases due to colony relocation between 1994 and 1995, all colonies that were found close to mounds inhabited in 1994, but abandoned in 1995, were checked for similarity of worker genotype over five loci (see below). Three such cases were identified and these colonies were treated as identical with the ones located in the aban- 


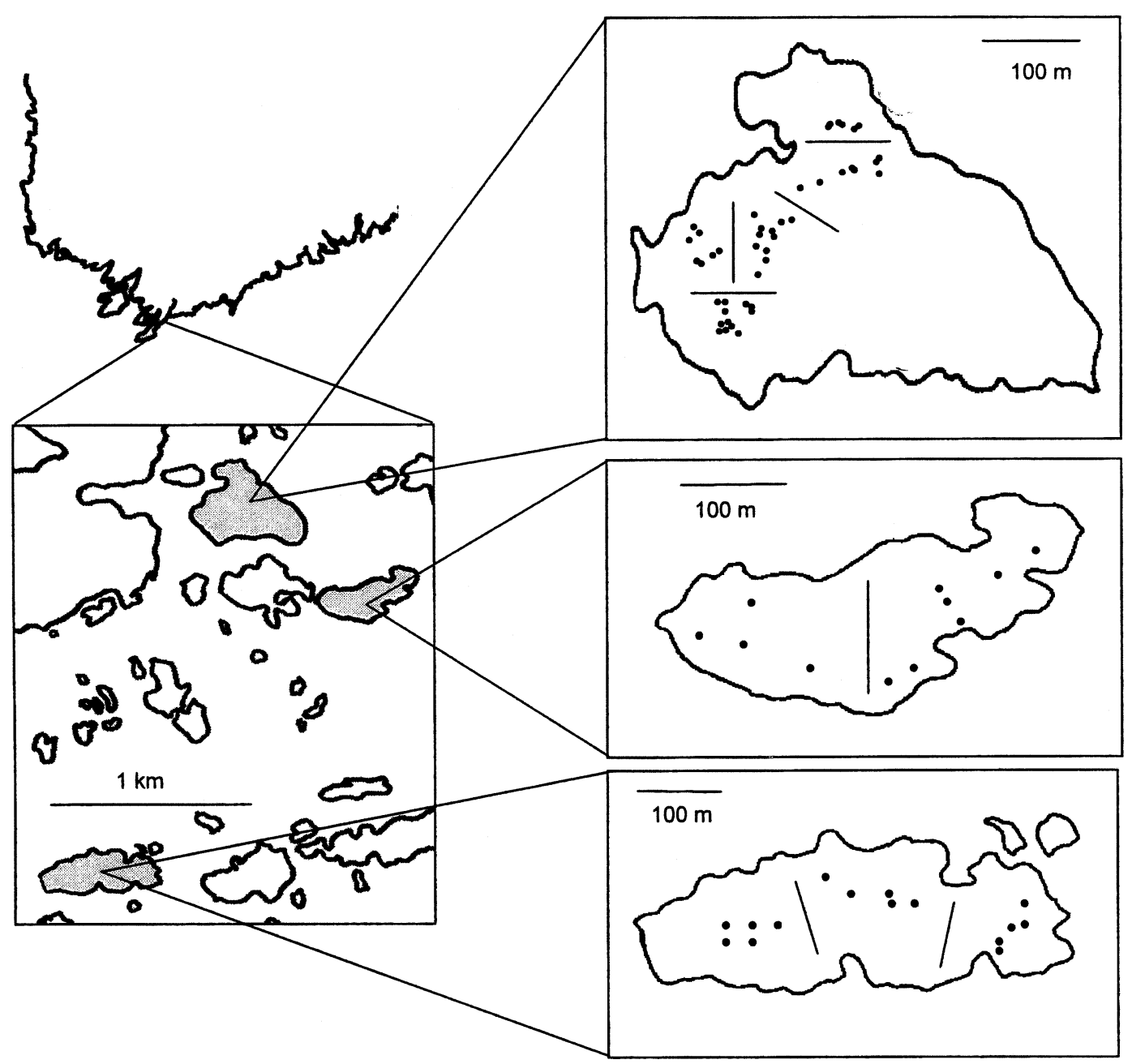

FIG. 1. Map of the study area and the location of nests on the three study islands. Shading indicates that the island is inhabited by Formica exsecta. The three study islands, Joskär, Kalvholmen, and Sundholmen, are shown in detail in the insets. The lines between the dots indicating the locations of nests delineate sector boundaries.

doned mounds nearby. In addition, the spatial location of all nests on the island harboring the largest number of nests $(n$ $=43$ ) was mapped by measuring the distance from each nest to at least one other nest and taking the compass direction between all such pairs of nests.

Ant colonies comprise three different castes: workers, which are diploid but largely sterile females, queens that are reproductive females, and haploid males that develop from unfertilized eggs by arrhenotoky. In species in which workers possess ovaries, some males can be worker-produced, but previous studies showed that all adult males are queen-produced in our study population (Sundström et al. 1996, Walin et al. 1998). Thus the genotypes of newly produced winged males directly reflect the genotype of the mother queen. Given the simple family structure with one queen and one or two (rarely more) colony fathers, the genotypes of queens and their male mates can be inferred based on the distribution of the genotypes of workers and winged males. In the cases in which males were not available ( 21 colonies), the parental genotypes were inferred from worker genotypes assuming a minimum number of fathers per colony. In seven cases all workers were heterozygous at one locus, which means that the exact identity of the alleles carried by the queen and her male mate respectively could not be determined. In these cases we treated the alleles as missing. The maternal and paternal genotypes inferred in this way were then used as input in the statistical analyses.

At least 10 workers and 10 winged males (where available) were collected from each colony and genotyped at two DNAmicrosatellite and three allozyme loci, all of which were polymorphic (Appendix). The procedures and running conditions were as given in Chapuisat (1996) and Seppä (1992), respectively. In total 710 workers and 503 males were genotyped. For 580 workers and 407 males the genotypes at all five loci were obtained, and the genotype at the most informative locus (FL21) was available for all individuals. Based on these data the multilocus genotypes of 70 queens and 94 colony fathers were inferred.

\section{Statistical Methods}

The data comprises several hierarchical levels spanning over individuals, colonies, sectors, and islands. Individual 
workers in ant colonies are related, so they do not represent independent samples. Therefore, we used a four-level hierarchical $F$-analysis of variance (Weir and Cockerham 1984; Weir 1996) for the worker data and a three-level analysis for the queen and paternal (colony father) data to obtain coefficients of identity by descent at the relevant level (Table 1). The analysis was performed with Genetic Data Analysis 1.1 (Lewis and Zaykin 1999). Confidence intervals were obtained by bootstrapping 5000 times over loci. In the analysis of worker data the lowest level comprised individuals within colonies, the next level colonies within sectors, the third level sectors within islands and the fourth level islands within the entire population. In the analysis of queen and paternal data, individuals within sectors represent the lowest level, sectors within islands the next level, and islands within the entire population the highest level. In addition, we tested for allele frequency differences between queens and colony fathers both across the entire population and per island with the exact tests of Genepop 3.1a (Raymond and Rousset 1995; available at http://www.cefe.cnrs-mop.fr/).

Because bootstrapping across five loci may produce spurious significant results if all estimates are by chance either below or above zero, we tested the significance of the different coefficients of identity by descent with the randomization tests implemented in Fstat 2.9.3 (Goudet 2001). The significance of the genetic differentiation among islands or sectors was tested by permuting genotypes 5000 times among islands or sectors, respectively, and using the log-likelihood $G$ statistic. Inbreeding was tested by permuting alleles 5000 times among individuals within sectors and estimating the $F_{\text {is. }}$. To accommodate the hierarchical structure of the data we analyzed each island separately, using the different sectors as populations. Dividing the material into smaller units greatly reduces the power of the analysis, so to avoid type II statistical errors we used Fisher's method for combining the probabilities of the three tests per island. By so doing we obtained a global test of differentiation among sectors for queens and colony fathers and a global test for inbreeding for queens. Because workers from the same colony are not independent, we resampled the data for the workers 100 times, each time selecting one worker per colony. We did this separately for each of the three islands, and analyzed each dataset with randomization tests for differentiation among sectors and inbreeding. We then calculated the combined probability across the three islands, ending up with 100 $P$-values for each set of three islands. Finally, to evaluate the overall significance of the genetic differentiation among sectors and inbreeding in workers, we used the mean significance level of those 100 analyses.

Isolation by distance was estimated at two levels. First, we tested for isolation by distance among sectors within the island harboring the largest number of colonies (Joskär, Fig. 1 ), then we did the same for individual queens, and colony fathers. We used Genepop 3.1a (Raymond and Rousset 1995) to estimate the genetic differentiation $\left(F_{\mathrm{sp}}\right)$ between all pairs of sectors on the island. The corresponding metric distances were calculated by averaging the distance between each nest in one sector to each nest in another sector. We calculated the relatedness between all pairs of queens, and between all pairs of colony fathers, respectively, by using the paired re- latedness option in Kinship 1.2 (Queller and Goodnight 1989, available at http://gsoft.smu.edu/GSoft.html). This estimate of relatedness provides an unbiased measure of genetic similarity between individuals (Lynch and Ritland 1999). We used the current sample (i.e. all queens or all colony fathers respectively) for calculating the background allele frequencies. In this situation the population-wide relatedness averaged over all pairs of individuals is by definition zero (Queller and Goodnight 1989). Individuals that are more similar to each other than any random pair of individuals will get a positive relatedness value, whereas those more dissimilar to each other than a random pair of individuals will get a negative relatedness value.

The correlation between the matrix of metric distances and the matrix of paired estimates of genetic differentiation and relatedness, respectively, was tested with Mantel's test following Manly's (1997) algorithm, now available in Fstat 2.9.3 (Goudet 2001). We thus obtained the exact probability for the matrix correlation, as well as the standard deviation of the matrix correlation coefficient under the null hypothesis (null model). The confidence intervals of the null model were constructed from the standard deviations with df $=n-1$, where $n=$ number of rows in the matrix. The paired values for genetic differentiation between sectors $\left(F_{\mathrm{sp}}\right)$ were transformed by $F_{\mathrm{sp}} /\left(1-F_{\mathrm{sp}}\right)$, and the metric distance values were ln-transformed. Finally, based on the regression slope from the matrix correlation we estimated the neighborhood size as described in Rousset (1997).

Sex-specific differences in dispersal can also be tested with assignment tests (Mossman and Waser 1999). We used the assignment tests described by Goudet et al. (2002), and implemented in Fstat 2.9.3 (Goudet 2001). A positive assignment value indicates that an individual is genetically more similar to the other individuals in the population in which it was found than would be expected by chance (a likely resident). By contrast, a negative value indicates that an individual is genetically less similar to the other individuals in the population in which it was found than would be expected by chance (a likely disperser). The biased dispersal option in Fstat calculates a mean assignment index $(A I c)$ corrected for variation in gene diversity across subsamples, as well as its variance $(v A I c)$. If dispersal is sex-biased, the sex that disperses more tends to have a lower mean $A I c$ value than the more philopatric sex. Conversely, the variance of $A I c$ $(v A I c)$ is expected to be higher for the sex that disperses more than for the more philopatric sex. This is because the former will include both residents (with common genotypes and high $A I c$ ) and immigrants (with rare genotypes and low $A I c$ ), whereas the latter will include mostly residents with high AIc. To test whether the two values differed significantly between queens and colony fathers we used the randomization procedures available in Fstat 2.9.3.

The relatedness among nestmate workers, between queens and their mates, and between the colony fathers that mated with the same queen (whenever queens were multiple-mated) was calculated with Relatedness 4.2 (Queller and Goodnight 1989, available at http://gsoft.smu.edu/GSoft.html). Groups were weighted equally and the standard errors were obtained by jackknifing over groups. We calculated the relatedness with respect to the background allele frequencies calculated 
TABLE 2. Inbreeding and population differentiation among workers, queens, and colony fathers, estimated in a four-level $F$-analysis of variance. $F_{\text {is }}$ is the inbreeding coefficient expressing the extent of nonrandom mating within sectors, $F_{\text {sp }}$ gives the subdivision among sectors within islands, and $F_{\mathrm{pt}}$ the differentiation among islands.

\begin{tabular}{|c|c|c|c|c|c|c|c|c|}
\hline \multirow[b]{2}{*}{ Locus } & \multicolumn{3}{|c|}{ Workers } & \multicolumn{3}{|c|}{ Queens } & \multicolumn{2}{|c|}{ Colony fathers } \\
\hline & $F_{\text {is }}$ & $F_{\mathrm{sp}}$ & $F_{\mathrm{pt}}$ & $F_{\text {is }}$ & $F_{\mathrm{sp}}$ & $F_{\mathrm{pt}}$ & $F_{\mathrm{sp}}$ & $F_{\mathrm{pt}}$ \\
\hline FL21 & 0.131 & 0.022 & 0.017 & 0.014 & 0.042 & 0.033 & 0.015 & 0.015 \\
\hline FL20 & 0.084 & 0.103 & 0.001 & -0.061 & 0.061 & -0.032 & 0.162 & 0.016 \\
\hline $\mathrm{ACO}$ & 0.301 & 0.061 & 0.072 & 0.113 & 0.042 & 0.002 & 0.121 & 0.100 \\
\hline PGM & 0.123 & 0.034 & -0.044 & 0.044 & 0.123 & -0.034 & -0.083 & 0.019 \\
\hline Upper $95 \%$ CI & 0.221 & 0.084 & 0.025 & 0.043 & 0.101 & 0.022 & 0.122 & 0.048 \\
\hline
\end{tabular}

separately for each sector, using all available workers, queens, and colony fathers. Hence, the relatedness values reflect the genetic similarity of individuals compared to random individuals from the same sector, excluding the effect of genetic differentiation among sectors.

\section{RESULTS}

Based on the hierarchical analysis we found no significant genetic differentiation among islands for either queens or workers and a small but significant differentiation among islands for colony fathers (Table 2). By contrast, we found a significant differentiation among sectors within islands for both workers and queens, but not for colony fathers (Table 2 ). Randomization tests using the $G$-statistics gave identical results, except that a significant differentiation among islands was also found for queens ( $G$-test among islands: $P=0.0004$ for queens, $P=0.004$ for colony fathers). The genetic differentiation among sectors within islands was highly significant for queens and workers, but not for colony fathers (combined probabilities: $P=0.0002$ for queens, $P=0.32$ for colony fathers, and mean $P$ over 100 resamples $=0.036$ for workers). We found no significant allele frequency differences between colony fathers and queens (Table 3).

The analysis of isolation by distance within the island of Joskär confirmed the pattern revealed by the $F$-statistics, and strongly suggests sex-biased gene flow in $F$. exsecta. First, the degree of genetic differentiation of queens, estimated as the paired $F_{\text {sp }}$ values for all pairs of sectors, increased with the average distance between sectors, whereas no significant correlation was found for colony fathers (Table 4). Accord-

TABLE 3. Tests of allele frequency differences between colony fathers $(n=94)$ and colony queens $(n=70)$. The probabilities of genic differentiation between colony fathers and females were obtained with exact tests. JSK, Joskär; KH, Kalvholmen; SH, Sundholmen.

\begin{tabular}{lcllll}
\hline \hline & \multirow{2}{*}{$\begin{array}{c}\text { No. of } \\
\text { alleles }\end{array}$} & \multicolumn{5}{c}{ Genic differentiation } \\
\cline { 3 - 6 } & 26 & 0.36 & 0.11 & 0.12 & 0.18 \\
\hline FL21 & 2 & 0.25 & 0.74 & 0.53 & 0.30 \\
FL20 & 2 & 1.0 & 0.72 & 1.0 & 1.0 \\
MDH & 2 & 0.15 & 1.0 & 1.0 & 0.59 \\
ACO & 2 & 0.09 & 1.0 & 0.19 & 0.36 \\
PGM & & 0.22 & 0.81 & 0.53 & 0.53 \\
All & & & & & SH \\
\hline
\end{tabular}

ingly, the sizes of the local breeding populations, as defined by $4 \pi \mathrm{D} \sigma^{2}$ in Rousset (1997), were 22 for queens and 50 for colony fathers, as estimated from the regression slope (neighborhood size $=1 / b$, where $b=0.045$ for queens and $b=$ 0.02 for colony fathers). More importantly, the degree of relatedness between pairs of individual queens decreased significantly with the metric distance, whereas no correlation was detected for pairs of individual colony fathers. This difference between queens and males cannot simply be attributed to a lack of power in the analyses of male data because the standard deviations of the null models were similar for both sexes. Furthermore, there was no overlap between the confidence limits of the null model for males and the correlation coefficient for queens in either the between-sector or the individual data (Table 4).

Male-biased dispersal was further supported by the assignment tests. First, the mean assignment index $A I c$ was significantly greater for queens than for colony fathers (queens: $A I c=0.33, n=70$; fathers: $A I c=-0.24, n=94$, $t=2.3, P=0.01)$. This indicates that females are the more philopatric sex, as they are more often assigned to their population of residence than are colony fathers. Similarly, the variance in the assignment index was significantly higher for colony fathers than for females (queens: $v A I c=1.52, n=$ 70; fathers: $v A I c=3.01, n=94, t=2.6, P=0.005$ ), which

TABLE 4. Isolation by distance on the island Joskär for both the five separate sectors and for all pairs of individuals. The betweensectors analysis is based on pairwise $F_{\mathrm{sp}}$-values calculated with Genepop 3.1a (Raymond and Rousset 1995). The between-individual analysis is based on pairwise relatedness calculated with Kinship 1.3 (Queller and Goodnight 1989). SD denotes the standard deviations of the matrix correlation coefficient $(R)$ under the null hypothesis, and the $95 \%$ confidence limits of the null model were calculated from the standard deviations with $n$ given by the number of rows in the respective matrices.

\begin{tabular}{llrr}
\hline \hline & & Queens & \multicolumn{1}{c}{$\begin{array}{c}\text { Colony } \\
\text { fathers }\end{array}$} \\
\hline Between sectors & one-tailed $\mathrm{p}$ & 0.01 & 0.23 \\
& $R$ & 0.60 & 0.18 \\
& SD & 0.27 & 0.31 \\
Between individuals & on\% CI & \pm 0.32 & \pm 0.37 \\
& $R$ & $<0.01$ & $>0.46$ \\
& SD & -0.13 & 0.01 \\
& $95 \% \mathrm{CI}$ & 0.04 & 0.03 \\
& \pm 0.01 & \pm 0.01 \\
\hline
\end{tabular}


TABLE 5. Relatedness $(r)$ among nestmate workers, between queens $(n=70)$ and their male mates $(n=94)$, and between two males mated to the same queens $(n=22)$.

\begin{tabular}{|c|c|c|c|c|c|c|}
\hline \multirow[b]{2}{*}{ Locus } & \multicolumn{2}{|c|}{ Workers } & \multicolumn{2}{|c|}{ Queen-male } & \multicolumn{2}{|c|}{ Male-male } \\
\hline & $r$ & SE & $r$ & SE & $r$ & SE \\
\hline FL21 & 0.73 & 0.02 & 0.16 & 0.07 & 0.10 & 0.08 \\
\hline FL20 & 0.65 & 0.05 & 0.13 & 0.19 & -0.11 & 0.21 \\
\hline $\mathrm{MDH}$ & 0.69 & 0.12 & 0.42 & 0.28 & 0.01 & 0.31 \\
\hline $\mathrm{ACO}$ & 0.71 & 0.15 & 0.67 & 0.30 & 0.01 & 0.30 \\
\hline PGM & 0.71 & 0.07 & 0.22 & 0.24 & 0.11 & 0.22 \\
\hline All & 0.71 & 0.03 & 0.23 & 0.08 & 0.04 & 0.06 \\
\hline
\end{tabular}

again is the expected pattern with a higher degree of philopatry of females than males.

Interestingly, the degree of inbreeding due to nonrandom mating was high and significantly greater than zero for workers, but close to and not significantly different from zero for queens (Table 2). Randomization tests using $F_{\text {is }}$, and performed separately for each of the three islands with the sectors defined as populations, confirmed the occurrence of significant inbreeding for workers (combined probability across the three islands and averaged over the 100 resamples: $P=$ 0.006), but not for queens (combined probability across the three islands: $P=0.48$ ).

In agreement with the positive inbreeding coefficient for workers, queens were significantly related to their male mates (Table 5). Indeed, the observed regression relatedness between queens and their male mates was 0.23 , which is roughly twice the inbreeding coefficient in workers (0.14), as expected in a male-haploid female-diploid species (Hartl and Clark 1989, p. 564; Chapuisat and Keller 1999). In these calculations the effect of population subdivision in queens was factored out as the relatedness estimates were calculated against the sector-specific background allele frequencies. Because queens were not inbred and males are haploid, no further inbreeding correction was needed.

The relatedness between males that co-sired a colony did not differ significantly from zero, which is consistent with male-biased dispersal (Table 5). The confidence limits overlapped with zero for all loci (Table 5). However, the power of this test is low and the standard error large, owing to a small sample size and the availability of only two genotypes per group. The relatedness among males mated to the same queen is likely to be an underestimate, as some double inseminations by closely related males may have remained undetected despite the high genetic resolution of one of the markers (Appendix). This underestimation can be corrected using a procedure derived from that presented in Pedersen and Boomsma (1999c), which gives a corrected estimate of male-male relatedness of 0.07 (J. S. Pedersen, pers. comm.).

The relatedness among nestmate workers was 0.71 (Table 5 ), but because workers were inbred in our population, we applied the inbreeding correction suggested by Pamilo (1985), which gave a relatedness of 0.62. This relatedness value corresponds to an effective mating frequency of 1.30. The effective mating frequency takes into account unequal contribution by colony fathers, and therefore is lower than the absolute mating frequency. To check the internal consistency of the relatedness, inbreeding, and mating frequency data, the effective mating frequency was also calculated as the harmonic mean effective paternity in each colony. The effective paternity was 1.0 in the 34 colonies headed by single-mated queens, 1.82 in the 19 colonies with double-mated queens, and 2.36 in the three colonies with queens mated to three males (Sundström et al. 1996; Walin et al. 1998). This gives an overall estimate of effective paternity equal to 1.23 , assuming no inbreeding. This value is in good agreement with the one obtained from the inbreeding-adjusted relatedness value, suggesting that the data on relatedness, inbreeding, and queen mating frequency are fully coherent.

\section{Discussion}

The objective of this study was to assess the mating system and dispersal patterns of males and females in a monogyne species of ants, $F$. exsecta. Monogyny is generally associated with extensive mating flights (Hölldobler and Wilson 1990; Bourke and Franks 1995; Crozier and Pamilo 1996), which has led to the common view that inbreeding should be rare and that high levels of gene flow are mediated through both males and females. Opposite to these expectations, we found evidence of strong inbreeding and sex-biased gene flow with limited female dispersal.

The genetic data comprised both microsatellites and allozymes, which differ in their information content. Highly variable microsatellite loci provide very precise information on genealogical relationships. In this study one locus was highly variable (24 alleles), and as expected the confidence intervals were narrower for this locus compared to the other four that had only two alleles. In general, the different loci gave similar results. The allozyme locus ACO gave the highest inbreeding estimates for both workers and queens (Table 2). However, this locus might be less reliable than the others, because the allele frequencies were very unequal with a global frequency of the less common allele below 10\%. In any case the high inbreeding value obtained for this locus had only a negligible impact on the overall results across loci since the global analyses weigh loci according to their information content. Because the number of loci was small, some caution is called for in the interpretation of the results. In particular, the $95 \%$ confidence intervals obtained by bootstrapping over loci in the four-level hierarchical $F$-analysis of variance may not be very reliable. Therefore, we used multiple approaches (three-level hierarchical analyses with randomization tests, tests of isolation by distance, and assignment tests) to confirm the robustness of the main findings.

We found a significant degree of population subdivision at a local scale (i.e. among sectors) for queens and workers, but not for males (the colony fathers). By contrast, we found only weak evidence for population subdivision at a larger scale (i.e. among islands). The coefficients of identity by descent for workers fall between the values obtained for queens and colony fathers both at the between-sectors and between-islands levels. This is expected, as the workers represent the combined allele frequencies of the queens and colony fathers. The lack of differentiation among islands may imply that the colonization of the islands is fairly recent, so that genetic drift has not been powerful enough to lead to an overall genetic differentiation among islands. That significant 
population structure for females is more pronounced at a local (between sectors) than at a global (between islands) scale is probably due to the smaller effective population size $(\mathrm{Ne})$ of sectors compared to islands.

The lack of differentiation among sectors for colony fathers suggests that males disperse more than females at a local scale. However, this result should be interpreted with caution because the $F_{\text {sp }}$ estimate for colony fathers has a large confidence interval, overlapping with that of queens (Table 2). Stronger evidence for sex-biased gene flow comes from the analysis of isolation by distance on the largest island, as well from the assignment tests across the entire population. The genetic relatedness between pairs of individual queens significantly decreased with geographic distance (Table 4). This isolation by distance indicates restricted dispersal of queens. By contrast, we found no such pattern for colony fathers. Corroborating this, the genetic differentiation between pairs of sectors increased with the geographic distance for queens, but not for colony fathers (Table 4). Similarly, both the mean assignment values $(A I c)$ and their variances $(v A I c)$ differed significantly between queens and colony fathers, further demonstrating that females are more philopatric than males.

Queens may also contribute to the dispersal of male genes if they first mate close to the nest and subsequently disperse with the male's sperm stored in their spermatheca. Thus two sources of gene flow through males exist, precopulation dispersal by individual males, and postcopulation dispersal by sperm carried in the spermathecae of dispersing females. Hence, a low rate of postcopulation dispersal in females may add to the amount of gene flow mediated by males. This may contribute to the lack of within-island genetic differentiation in colony fathers. Conversely, a considerable degree of population viscosity (continuous isolation by distance) in females compared to males is fully consistent with the existence of mating swarms as a prominent feature of this species. The vast majority of females may disperse on the wing, but if most of them perish, and those few that do not disperse have a greater colony-founding success, then a pattern with related queens within patches follows.

This study demonstrates that sex-specific dispersal can be uncovered without comparing mitochondrial and nuclear markers when data on nuclear genes are available for males and females sampled after dispersal (Vitalis 2002; Goudet et al. 2002). To date, this approach has been applied in a few other species and has revealed sex-biased dispersal in common shrews (Favre et al.1997); Cunningham's skink, Egernia cunninghami (Stow et al. 2001); noctule bats, Nyctalus noctula (Petit et al. 2001); red-billed quelea, Quelea quelea (Dallimer et al. 2002); and river otters, Lontra canadensis (Blundell et al. 2002). High dispersal by one sex only should tend to homogenize allele frequencies among subpopulations. However, dispersal through one sex only is often not sufficient to generate complete panmixis, so that small but significant allele frequency differences between the sexes can prevail when individuals are sampled after dispersal (Goudet et al. 2002). Alternatively, genetic differences among sectors may indicate that the populations are not at equilibrium, or that complex interactions between breeding system, sex ratios, and demography prevail (Prugnolle and DeMeeus 2002). In $F$. exsecta the fact that many colonies produce predomi- nantly one sex may further accentuate such complexity (Sundström et al. 1996).

Although sex-biased dispersal should tend to reduce inbreeding (Dobson 1982), we found strong and significant inbreeding in workers $\left(F_{\text {is }}=0.14\right)$. Moreover, the relatedness between queens and their male mate(s) was also high and significant (regression $r=0.23$ ). These high values indicate that mating occurs on average between fairly close relatives, as the regression relatedness between sisters and brothers is 0.50 in haplodiploids (Crozier and Pamilo 1996). An inbreeding coefficient $(F)$ of 0.14 corresponds to approximately $40 \%$ full-sib mating given the relation $F=D /(4-3 D)$, where $D$ is the frequency of sib mating (Suzuki and Iwasa 1980).

The most likely explanation for the cooccurrence of sexbiased dispersal and inbreeding is that males exhibit alternative dispersal and mating strategies. Two male morphs with different dispersal inclinations have been described (Fortelius et al. 1987). Large males are produced in colonies that also produce females, and they show less flight activity than small males that predominate in colonies producing males only (Fortelius et al. 1987). Hence, it is likely that some queens mate with large males within or close to their natal nest, leading to sib mating, whereas others mate with unrelated, presumably small, males. The suggestion that some females mate close to their nest is supported on one hand by the finding that females are less inclined to fly than males in laboratory tests (Fortelius et al. 1987) and, on the other hand, by our genetic data indicating isolation by distance for queens.

Brother-sister mating is likely to impose a high cost on colony survival. If there is one sex-determining locus, half of the cases of brother-sister mating result in 50\% of the offspring being diploid males. This occurs when both parents carry identical alleles at the sex-determining locus (i.e. matched mating; Cook and Crozier 1995). Because diploid males are produced instead of workers and contribute no work for the colony, they impose a high cost on incipient colonies. No diploid males have been found in our study population (Sundström et al. 1996), and two alternative mechanisms may explain this absence. First, diploid males might be eliminated before pupation. Second, colonies headed by a queen that had a matched mating may not survive through the colony founding stage (Pamilo et al. 1994). If this second hypothesis is true, the initial frequency of brother-sister mating may be twice as high as indicated by the average queen-male relatedness in mature colonies.

At first view, the observed high frequency of brother-sister mating is surprising given that $F$. exsecta colonies produce mostly single-sex broods (Sundström et al. 1996). However, sex-ratio specialization is not complete in $F$. exsecta; approximately $36 \%$ of the colonies produce a mixed brood (Sundström et al. 1996), which provides ample opportunities for brother-sister mating. Indeed, the frequency of colonies producing mixed-sex broods fits remarkably well with the estimated proportion of full-sib matings of $40 \%$.

Interestingly, we found no inbreeding in queens. The difference between queens and workers in the amount of inbreeding was clearly significant; the confidence limits of the two estimates did not overlap (Table 2). Similarly, the randomization tests failed to detect any inbreeding in queens, 
whereas $97 \%$ of the analyses based on resampled datasets indicated significant inbreeding in workers. Such differences between queens and workers in the degree of heterozygosity have previously been recorded twice, in Aphaenogaster rudis (Crozier 1973) and Formica truncorum (Sundström 1993). There are at least three possible explanations for this. First, inbred female larvae might be more likely to develop into workers than queens compared to outbred larvae (note that all offspring from the same mating will be equally inbred). If so, this means that colonies with an incestuous queen will produce only or predominantly males. However, we found no correlation between colony sex ratios and queen-male relatedness $\left(r^{2}=0.03, n=66, P>0.1\right)$. Second, inbred queens might be less successful during colony foundation. For example, higher heterozygosity may confer a selective advantage through higher fecundity or better survival. Third, the population might be young and not yet at equilibrium, with some queens representing the initial colonizers or their first generation descendants. However, the latter hypothesis is unlikely to account for such a dramatic change in the average inbreeding coefficient between two consecutive generations.

Our finding of population viscosity in queens and workers in conjunction with inbreeding in workers is surprising for a monogyne ant, and stands in contrast to the traditional view that monogyny is associated with high rates of dispersal and outbreeding (Hölldobler and Wilson 1990; Bourke and Franks 1995; Crozier and Pamilo 1996). Among the studies that have analyzed the genetic population structure in monogyne ants (Pamilo 1983; Pamilo and Rosengren 1984; Pamilo 1991; Sundström 1993; Hasegawa and Yamaguchi 1995; Seppä and Pamilo 1995; Shoemaker and Ross 1996; Cole and Wiernasz 1997; Ross et al. 1997, 1999), four have found significant levels of inbreeding. Two concerned the population of $F$. exsecta analyzed in the present study (Pamilo and Rosengren 1984; Pamilo 1991), and a third was interpreted as the result of population subdivision due to a very low number of colonies participating in nuptial flights at any one time (Hasegawa and Yamaguchi 1995). The fourth study found significant amounts of sib mating in a lek-mating species, Pogonomyrmex occidentalis (Cole and Wiernasz 1997), but this result could not be repeated in a later study (Cole and Wiernasz 1999).

Moderate levels of inbreeding and isolation by distance seem more common in polygyne ants, including some Formica species (Seppä 1992; Sundström 1993; Crozier and Pamilo 1996; Chapuisat et al. 1997; Pamilo et al. 1997; Chapuisat and Keller 1999). A general difficulty in assessing the level of inbreeding and the amount of population genetic differentiation is to identify the relevant spatial scale at which these should be measured (Queller 1994). This is highlighted by our data; we found very little differentiation at a larger scale (i.e. among islands), but significant differentiation at a smaller scale (within islands). This clearly calls for multilevel approaches in population analysis.

Our results illustrate that although the general breeding structure is one that apparently promotes dispersal and outbreeding, the resulting genetic pattern may be very complex, resting on a delicate balance between outbreeding and longrange dispersal on the one hand and inbreeding and local dispersal on the other. Alternatively, the pattern seen here may represent a nonequilibrium case in which the level of inbreeding is building up within the population. The results also highlight the fact that presumably well-dispersing species may have fairly limited colonization abilities. This also raises concerns for conservation, as habitat fragmentation due to human actions is rapidly increasing.

\section{ACKNOWLEDGMENTS}

We thank J. Goudet for providing software for the Mantel tests; H. Ảberg and R. Forsman for help in the field; E. Petit, J. S. Pedersen, P. Jarne, and two anonymous reviewers for constructive comments. The study was financed by the Academy of Finland (grant no. 42725, LS), the University of Helsinki (LS), several grants from the Swiss National Science Foundation (LK, MC), and the European Union network INSECTS.

\section{Literature Cited}

Banschbach, V. S., and J. M. Herbers. 1996. Complex colony structure in social insects: I. Ecological determinants and genetic consequences. Evolution 50:285-297.

Blundell, G. M., M. Ben-David, P. Groves, R. T. Bowyers, and E. Geffen. 2002. Characteristics of sex-biased dispersal and gene flow in coastal river otters: implications for natural recolonization or extirpated populations. Mol. Ecol. 11:289-303.

Boomsma, J. J., and L. Sundström. 1998. Patterns of paternity skew in Formica ants. Behav. Ecol. Sociobiol. 42:85-92.

Bourke, A. F. G., and N. R. Franks. 1995. Social evolution in ants. Princeton Univ. Press, Princeton, NJ.

Breden, F., and M. J. Wade. 1991. "Runaway" social evolution: reinforcing selection for inbreeding and altruism. J. Theor. Biol. 151:323-337.

Chapuisat, M. 1996. Characterization of microsatellite loci in Formica lugubris B and their variability in other ant species. Mol. Ecol. 5:599-601.

Chapuisat, M., and L. Keller. 1999. Extended family structure in the ant Formica paralugubris: the role of the breeding system. Behav. Ecol. Sociobiol. 46:405-412.

Chapuisat, M., J. Goudet, and L. Keller. 1997. Microsatellites reveal high population viscosity and limited dispersal in the ant Formica paralugubris. Evolution 51:475-482.

Chesser, R. K. 1991. Influence of gene flow and breeding tactics on gene diversity within populations. Genetics 129:573-583.

Chesser, R. K., O. E. Rhodes, D. W. Sugg, and A. Schnabel. 1993. Effective sizes for subdivided populations. Genetics 135: 1221-1232.

Cole, B. J., and D. C. Wiernasz. 1997. Inbreeding in a lek-mating ant species, Pogonomyrmex occidentalis. Behav. Ecol. Sociobiol. 40:79-86.

. 1999. The selective advantage of low relatedness. Science 285:891-893.

Cook, J. M., and R. H. Crozier. 1995. Sex determination and population biology in the Hymenoptera. Trends Ecol. Evol. 10: 281-286.

Crnokrak, P., and D. A. Roff. 1999. Inbreeding depression in the wild. Heredity 83:260-270.

Crozier, R. H. 1973. Apparent differential selection at an isozyme locus between queens and workers of the ant Aphaenogaster rudis. Genetics 73:313-318.

Crozier, R. H., and P. Pamilo. 1996. Evolution of social insect colonies: sex allocation and kin selection. Oxford Univ. Press, Oxford, U.K

Dallimer, M., C. Blackburn, P. J. Jones, and J. M. Pemberton. 2002. Genetic evidence for male biased dispersal in the red-billed quelea Quelea quelea. Mol. Ecol. 11:529-533.

Dobson, F. S. 1982. Competition for mates and predominant juvenile dispersal in mammals. Anim. Behav. 30:1183-1192.

Dobson, F. S., R. K. Chesser, J. L. Hoogland, D. W. Sugg, and D. 
W. Foltz. 1997. Do black-tailed prairie dogs minimize inbreeding? Evolution 51:970-978.

Favre, L., F. Balloux, J. Goudet, and N. Perrin. 1997. Female-biased dispersal in the monogamous mammal Crocidura russula: evidence from field data and microsatellite patterns. Proc. R. Soc. Lond. B 264:127-132.

Fortelius, W., P. Pamilo, R. Rosengren, and L. Sundström. 1987. Male size dimorphism and alternative reproductive tactics in Formica exsecta ants (Hymenoptera: Formicidae). Ann. Zool. Fenn. 24:45-54.

Goodisman, M. A. D., and K. G. Ross. 1998. A test of queen recruitment models using nuclear and mitochondrial markers in the fire ant Solenopsis invicta. Evolution 52:1416-1422.

Greenwood, P. J. 1980. Mating systems, philopatry and dispersal in birds and mammals. Anim. Behav. 28:1140-1162.

Goudet, J. 2001. FSTAT, a program to estimate and test gene diversities and fixation indices Ver. 2.9.3. Available from http:// www.unil.ch/izea/softwares/fstat.html.

Goudet, J., N. Perrin, and P. Waser. 2002. Tests for sex-biased dispersal using bi-parentally inherited markers. Mol. Ecol. 11: $1103-1114$.

Hartl, D. L., and A. G. Clark. 1989. Principles of population genetics. Sinauer Associates, Sunderland, MA.

Hasegawa, E., and T. Yamaguchi. 1995. Population structure, local mate competition, and sex-allocation pattern in the ant Messor aciculatus. Evolution 49:260-265.

Herbers, J. M., and S. Grieco. 1994. Population structure of Leptothorax ambiguus, a facultatively polygynous, polydomous ant species. J. Evol. Biol. 7:581-598.

Hölldobler, B., and E. O. Wilson. 1990. The ants. Springer-Verlag, Berlin.

Keller, L. 1993. Queen number and sociality in insects. Oxford Univ. Press, Oxford, U.K.

1995. Social life: the paradox of multiple-queen colonies. Trends Ecol. Evol. 10:355-360.

Keller, L. F., P. Arcese, J. N. M. Smith, W. M. Hochachka, and S. C. Stearns. 1995. Selection against inbred song sparrows during a natural population bottleneck. Nature 372:356-357.

Keller, L., L. Sundström, and M. Chapuisat. 1997. Male reproductive success: paternity contribution to queens and workers in Formica ants. Behav. Ecol. Sociobiol. 41:11-15.

Lewis, P. O., and D. Zaykin. 1999. Genetic Data Analysis1.0 (d12), a computer program for the analysis of allelic data. Available at http://lewis.eeb.uconn.edu/lewishome/software.html.

Lynch, M., and K. Ritland. 1999. Estimation of pairwise relatedness with molecular markers. Genetics 152:1753-1766.

Manly, B. F. J. 1997. Randomization, bootstrap and Monte Carlo methods in biology. Chapman and Hall, London.

Mossman, C. A., and Waser, P. M. 1999. Genetic detection of sexbiased dispersal. Mol. Ecol. 8:1063-1067.

Nei, M. 1987. Molecular evolutionary genetics. Columbia Univ. Press, New York.

Nunney, L. 1993. The influence of mating system and overlapping generations on effective population size. Evolution 47: 1329-1341.

Pamilo, P. 1982. Genetic population structure in polygynous Formica ants. Heredity 48:95-106.

- 1983 . Genetic differentiation within subdivided populations of Formica ants. Evolution 37:1010-1022.

. 1985. Effect of inbreeding on genetic relatedness. Hereditas 103:195-200.

- 1991. Life span of queens in the ant Formica exsecta. Insect Soc. 38:111-119.

Pamilo, P., and R. Rosengren. 1984. Evolution of nesting strategies of ants: genetic evidence from different population types of Formica ants. Biol. J. Linn. Soc. 21:331-348.

Pamilo, P., L. Sundström, W. Fortelius, and R. Rosengren. 1994. Diploid males and colony-level selection in Formica ants. Ethol. Ecol. Evol. 6:221-235.

Pamilo, P., P. Gertsch, P. Thorén, and P. Seppä. 1997. Molecular population genetics of social insects. Annu. Rev. Ecol. Syst. 28: $1-25$.

Pedersen, J. S., and J. J. Boomsma. 1999a. Genetic analysis of colony structure in polydomous and polygynous ant populations. Biol. J. Linn. Soc. 66:115-144.

1999b. Effect of habitat saturation on the number and turnover of queens in the polygynous ant, Myrmica sulcinodis. J. Evol. Biol. 12:903-917.

- 2 1999c. Multiple paternity on social Hymenoptera: estimating the effective mate number in single-double mating populations. Mol. Ecol. 8:577-587.

Petit, E., F. Balloux, and J. Goudet. 2001. Sex-biased dispersal in a migratory bat: a characterization using sex-specific demographic parameters. Evolution 55:635-640.

Prugnolle, F., and T. de Meeus. 2002. Inferring sex-biased dispersal from population genetic tools: a review. Heredity 88:161-165.

Queller, D. C. 1994. Genetic relatedness in viscous populations. Evol. Ecol. 8:70-73.

Queller, D. C., and K. F. Goodnight. 1989. Estimating relatedness using genetic markers. Evolution 242:258-275.

Raymond, M., and F. Rousset. 1995. GENEPOP (ver. 1.2): a population genetics software for exact tests and ecumenicism. J. Hered. 86:248-249.

Rosengren, R., L. Sundström, and W. Fortelius. 1993. Monogyny and polygyny in Formica ants: the result of alternative dispersal tactics. Pp. 308-333 in L. Keller, ed. Queen number and sociality in insects. Oxford Univ. Press, Oxford, U.K.

Ross, K. G. 1993. The breeding system of the fire ant Solenopsis invicta: effects on colony genetic structure. Am. Nat. 141: $554-576$.

. 2001. Molecular ecology of social behaviour: analyses of breeding systems and genetic structure. Mol. Ecol. 10:265-284.

Ross, K. G., and L. Keller. 1995a. Ecology and evolution of social organization: insights from fire ants and other highly eusocial insects. Annu. Rev. Ecol. Syst. 26:631-656.

- 1995b. Joint influence of gene flow and selection on a reproductively important genetic polymorphism in the fire ant Solenopsis invicta. Am. Nat. 146:325-348.

Ross, K. G., M. J. B. Krieger, D. D. Shoemaker, E. L. Vargo, and L. Keller. 1997. Hierarchical analysis of genetic structure in native fire ant populations: results from three classes of molecular markers. Genetics 147:643-655.

Ross, K. G., D. D. Shoemaker, M. J. B. Krieger, C. J. DeHeer, and L. Keller. 1999. Assessing genetic structure with multiple classes of molecular markers: A case study involving the introduced fire ant Solenopsis invicta. Mol. Biol. Evol. 16:525-543.

Rousset, F. 1997. Genetic differentiation and estimation of gene flow from $F$-statistics under isolation by distance. Genetics 145 : 1219-1228.

Saccheri, I., M. Kuussaari, M. Kankare, P. Vikman, W. Fortelius, and I. Hanski. 1998. Inbreeding and extinction in a butterfly metapopulation. Nature 392:491-494.

Seppä, P. 1992. Genetic relatedness of worker nestmates in Myrmica ruginodis (Hymenoptera:formicidae) populations. Behav. Ecol. Sociobiol. 30:253-260.

Seppä, P., and P. Pamilo 1995. Gene flow and population viscosity in Myrmica ants. Heredity 74:200-209.

Shoemaker, D. D., and K. G. Ross. 1996. Effects of social organization on gene flow in the fire ant Solenopsis invicta. Nature 383:613-616.

Stow, A. J., P. Sunnucks, D. A. Briscoe, and M. G. Gardner. 2001. The impact of habitat fragmentation on dispersal of Cunningham's skink (Egernia cunninghami): evidence from allelic and genotypic analyses of microsatellites. Mol. Ecol. 10:867-878.

Sugg, D. W., R. K. Chesser, F. S. Dobson, and J. L. Hoogland. 1996. Population genetics meets behavioral ecology. Trends Ecol. Evol. 11:338-342.

Sundström, L. 1993. Genetic population structure and sociogenetic organisation in Formica truncorum. Behav. Ecol. Sociobiol. 33: $345-354$.

- 1995. Dispersal polymorphism and physiological condition of males and females in the ant Formica truncorum. Behav. Ecol. 6:132-139.

Sundström, L., M. Chapuisat, and L. Keller. 1996. Conditional manipulation of sex ratios by ant workers: a test of kin selection theory. Science 274:993-995. 
Suzuki, Y. and Y. Iwasa. 1980. A sex ratio theory of gregarious parasitoids. Res. Popul. Ecol. 11:366-382.

Vitalis, R. 2002. Sex-specific genetic differentiation and coalescence times: estimating sex-biased dispersal rates. Mol. Ecol. $11: 125-138$.

Wade, M. J. 1985. The influence of multiple inseminations and multiple foundresses on social evolution. J. Theor. Biol. 112: 109-121.

Wade, M. J., and F. Breden. 1981. Effect of inbreeding on the evolution of altruistic behavior by kin selection. Evolution 35: 844-858.

Walin, L., L. Sundström, P. Seppä, and R. Rosengren. 1998. Worker reproduction in ants-a genetic analysis. Heredity 81:604-612.
Weir, B. S. 1996. Genetic data analysis II. Sinauer Associates, Sunderland, MA.

Weir, B. S., and C. C. Cockerham. 1984. Estimating $F$-statistics for the analysis of population structure. Evolution 38:1358-1370. Wright, S. 1921. Systems of mating. Genetics 6:111-178. 1931. Evolution in Mendelian populations. Genetics 16: 97-159.

—_. 1943. Isolation by distance. Genetics 28:114-138.

- 1951. The genetical structure of populations. Ann. Eugenics 15:323-354.

APPENDIX

Allele frequencies and Nei's (1987) unbiased estimate for gene diversity for queens and colony fathers per island and for the entire population as calculated with FSTAT 2.9.3 (Goudet 2001). JSK, Joskär; KH, Kalvholmen; SH, Sundholmen.

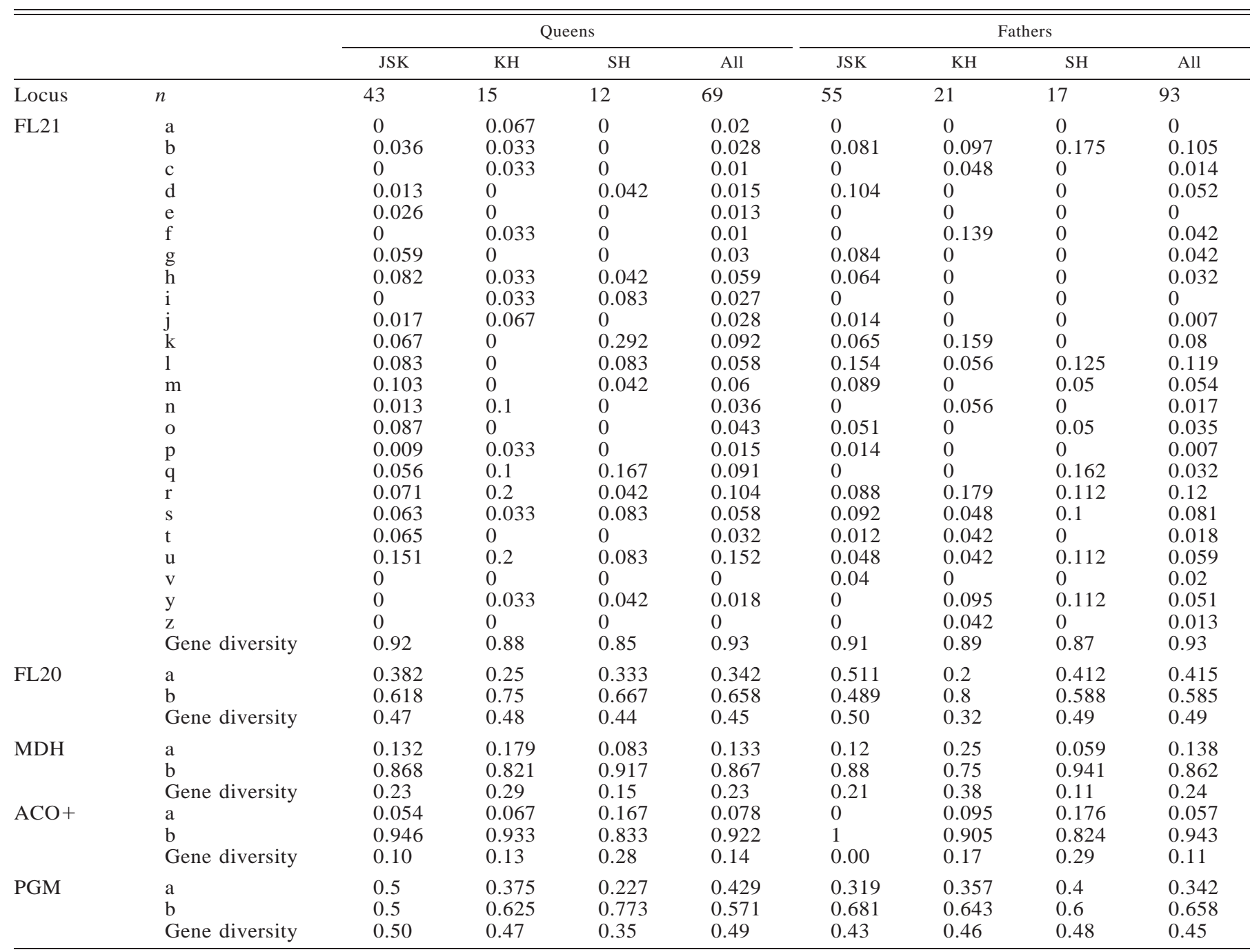

